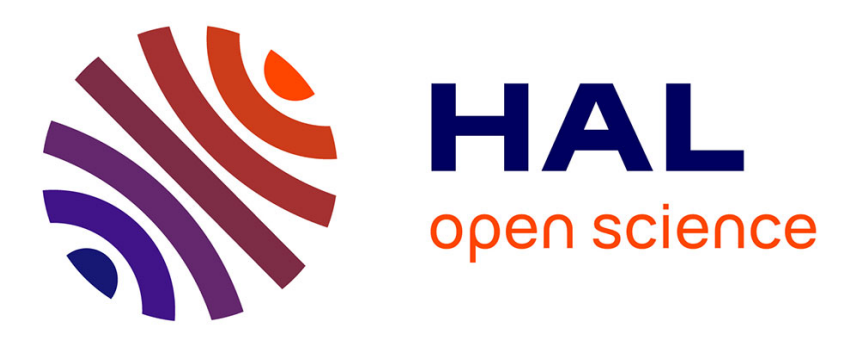

\title{
Energetic consequences of contrasting winter migratory strategies in a sympatric Arctic seabird duet
} Jérôme Fort, Harald Steen, Hallvard Strom, Yann Tremblay, Eirik Grønningsæter, Emeline Pettex, Warren P Porter, David Grémillet

\section{- To cite this version:}

Jérôme Fort, Harald Steen, Hallvard Strom, Yann Tremblay, Eirik Grønningsæter, et al.. Energetic consequences of contrasting winter migratory strategies in a sympatric Arctic seabird duet. Journal of Avian Biology, 2013, 44, pp.255-262. 10.1111/j.1600-048X.2012.00128.x . hal-01100392

\section{HAL Id: hal-01100392 \\ https://hal.science/hal-01100392}

Submitted on 19 Mar 2015

HAL is a multi-disciplinary open access archive for the deposit and dissemination of scientific research documents, whether they are published or not. The documents may come from teaching and research institutions in France or abroad, or from public or private research centers.
L'archive ouverte pluridisciplinaire HAL, est destinée au dépôt et à la diffusion de documents scientifiques de niveau recherche, publiés ou non, émanant des établissements d'enseignement et de recherche français ou étrangers, des laboratoires publics ou privés. 


\section{Energetic consequences of contrasting winter migratory strategies in a sympatric Arctic seabird duet}

Jérôme Fort $^{1,2^{*}}$, Harald Steen $^{3}$, Hallvard Strøm $^{3}$, Yann Tremblay $^{4}$, Eirik Grønningsæter ${ }^{3}$, Emeline Pettex ${ }^{1,5}$, Warren P. Porter ${ }^{6}$ \& David Grémillet ${ }^{1,7}$

${ }^{1}$ Centre d'Ecologie Fonctionnelle et Evolutive, UMR 5175 du CNRS, 1919 route de Mende, 34293 Montpellier cedex 5, France

2 Department of Bioscience, Aarhus University, Frederiksborgvej 399, 4000 Roskilde, Denmark

${ }^{3}$ Norwegian Polar Institute, Fram Centre, 9296 Troms $\varnothing$, Norway

${ }^{4}$ Institut de Recherche pour le Développement, UMR 212 EME, Centre de Recherche Halieutique, av. Jean Monnet, B.P. 171, 34203 Sète Cedex, France

${ }^{5}$ Centre de Recherches sur les Ecosystèmes d'Altitude, Observatoire du Mont-Blanc, 67 lacets du Belvédère, 74400 Chamonix, France

${ }^{6}$ Department of Zoology, University of Wisconsin, 250 N. Mills Street, Madison, Wisconsin 53706, USA

${ }^{7}$ Percy FitzPatrick Institute, DST/NRF Centre of Excellence, University of Cape Town, Rondebosch 7701, South Africa

*Correspondence author. E-mails: fort.jerome@gmail.com; jef@dmu.dk

Running head: winter ecology of North Atlantic seabirds 


\section{Summary}

At the onset of winter, warm-blooded animals inhabiting seasonal environments may remain resident and face poorer climatic conditions, or migrate towards more favourable habitats. While the origins and evolution of migratory choices have been extensively studied, their consequences on avian energy balance and winter survival are poorly understood, especially in species difficult to observe such as seabirds. Using miniaturized geolocators, time-depth recorders and a mechanistic model (Niche Mapper ${ }^{\mathrm{TM}}$ ), we investigated the migratory strategies, the activity levels and the energy expenditure of the closely-related, sympatrically breeding Brünnich's guillemots (Uria lomvia) and common guillemots (Uria aalge) from Bjørnøya, Svalbard. The two guillemot species from this region present contrasting migratory strategies and wintering quarters: Brünnich's guillemots migrate across the North Atlantic to overwinter off south-east Greenland and Faroe Islands, while common guillemots remain resident in the Barents, the Norwegian and the White Seas. Results show that both species display a marked behavioural plasticity to respond to environmental constraint, notably modulating their foraging effort and diving behaviour. Nevertheless, we provide evidence that the migratory strategy adopted by guillemots can have important consequences for their energy balance. Overall energy expenditure estimated for the non-breeding season is relatively similar between both species, suggesting that both southward migration and higharctic winter residency are energetically equivalent and suitable strategies. However, we also demonstrate that the migratory strategy adopted by Brünnich's guillemots allows them to have reduced daily energy expenditures during the challenging winter period. We therefore speculate that 'resident' common guillemots are more vulnerable than 'migrating' Brünnich's guillemots to harsh winter environmental conditions. 


\section{Introduction}

Seasonality affects most of the planet and fluctuating environmental conditions associated with this phenomenon impact endothermic animals by challenging their energy balance (McNamara et al. 2008). Winter-time for instance features an energetic bottleneck which potentially affects the survival of organisms in seasonal environments, and ultimately shapes their population dynamics (e.g. McNamara et al. 2008, Maldonado et al. 2009). Migration, which often results in the avoidance of difficult winter conditions via movement towards energetically less challenging areas (Berthold et al. 2003), appears as an attractive strategy to face winter energy constraints. Birds, with their ability to fly distances of up to several thousand kilometres (e.g. Egevang et al. 2010), are best-candidates for migration. Nevertheless, not all of them choose this strategy, and in the fall, birds from temperate to polar regions can decide to: 1) stay and overwinter in the same region as the one of their breeding season (residency), or 2) move towards lower latitudes (migration). Residency entails increased living costs due to degraded environmental conditions which migrants avoid. However, migration also affects avian energetics, notably through an increase in flight activity which requires elaborate energy management en route (Klaassen 1996; McWilliams et al. 2004). Migration timing, behaviour and associated costs also have a clear impact on bird fitness and survival (Møller 1994; Klaassen 2003). In this context there is the potential not for a single, but for a series of evolutionary stable strategies (see Newton 2008).

While passerines and waders are the primary targets of migration studies (Bearhop et al. 2005; Rolshausen et al. 2010), the seabird group has been largely neglected, essentially because of technical difficulties. Indeed, most seabirds are offshore during the entire non-breeding period, where they are difficult or even impossible to observe directly. This results in a lack of winter-time information about their movements, distribution, behaviour, and energetics. Such knowledge is nonetheless particularly important since this period is equally crucial for 
seabirds as it is to land birds, notably by conditioning adult winter survival (Lebreton et al. 1992). Today, the use of novel biotelemetry tools is rapidly opening new avenues in the study of the ecophysiology of wintering seabirds (e.g. Grémillet et al. 2005; Fort et al. 2012). Brünnich's guillemots (Uria lomvia) and common guillemots (Uria aalge) are among the most abundant seabird species of the North Atlantic and Arctic marine ecosystems (Gaston \& Jones 1998), and both of them play a crucial role in energy flow through Arctic marine food webs (Brooke 2004). Despite their obvious ecological importance and the regular occurrence of events of winter mass-mortality (Gaston \& Jones 1998; Gaston 2004), little is known about the non-breeding biology of these two closely-related species and how they are affected by winter conditions, particularly for populations from the eastern North Atlantic (but see Lorentsen \& May 2012). Interestingly, first results based on ring recoveries tend to indicate that sympatric populations of Brünnich's and common guillemots breeding in Svalbard respond differently to seasonal constraints, with Brünnich's guillemots migrating southward to winter off Newfoundland and southwest Greenland (Bakken \& Mehlum 2005), while common guillemots stay close to their breeding sites in the Barents and the Norwegian Seas (Gaston \& Jones 1998). These results can now be confirmed and detailed using miniaturized global location sensors (GLS, sensu Wilson et al. 1992), to identify migration routes and wintering patterns, and to investigate how different migratory and overwinter strategies might constrain seabird behaviour and energetics.

Using light-level geolocation and time-depth recorders, the present study therefore aimed to 1) study the migration patterns of Brünnich's and common guillemots from Bjørnøya, Svalbard to confirm that their populations adopt divergent migratory strategies, and to highlight their main wintering quarters. 2) Compare their behaviour and energetics over the entire non-breeding season to understand how they cope with the different environmental conditions encountered, and how distinct migratory responses affect their energy balance. 


\section{Methods}

\section{STUDY SITES, SPECIES AND DATA-LOGGERS}

During the 2007 breeding season, 25 geolocation archival tags (LTD 2400; Lotek Wireless, St. Johns, NF, Canada; mass in air $=5.5 \mathrm{~g}$; diameter $=11 \mathrm{~mm}$; length $=35 \mathrm{~mm}$ ) were deployed on common and Brünnich's guillemots nesting at Bjørnøya (Svalbard; $74^{\circ} 21^{\prime} \mathrm{N}, 1^{\circ} 05^{\prime} \mathrm{E}$; $\mathrm{n}=10$ and $\mathrm{n}=15$, respectively). Attached to conventional leg rings used for individual identification, these tags were programmed to record time, pressure, external temperature and light intensity every eight min through the 2007-2008 non-breeding period, defined as extending from 15 September 2007 to 31 May 2008. September 15th was chosen as a nonbreeding period starting date to avoid any bias in bird behaviour due to males accompanying their chick at sea after fledging (fledging occurs end of July for both guillemot species; Bakken \& Pokrovskaya 2000; Barrett \& Golovkin 2000), and due to moult and flightless constraints in late August/early September (Lorentsen \& May 2012, Supplementary material Appendix 1). An additional small amount of blood was sampled on each bird for subsequent molecular sexing.

In July 2008, all resighted equipped birds were recaptured at their colony. In total, five of the loggers deployed on Brünnich's guillemots were recovered. All of them successfully recorded pressure, light intensity and temperature. All 10 loggers deployed in common guillemots in 2007 were retrieved in 2008. Six of them successfully recorded all three parameters for the entire period, one successfully recorded light levels and the last four failed. The higher failure rate observed in common guillemot data-loggers is presumably due to colder water temperatures experienced by birds during the study period (see results) resulting in battery failure. 


\section{LIGHT-LEVEL GEOLOCATION ANALYSIS}

Animals' locations were estimated from light levels using Tremblay et al. (2009) method (see Tremblay et al. 2009 for details). Light-level geolocation data entail relatively large errors of about 100-200km (Teo et al. 2004; Shaffer et al. 2005) and are limited at high latitudes by either constant day or night, or equal day and night duration during equinoxes. In addition, the animal's behaviour might occasionally alter the quality of the light level readings (e.g. the sensor being shaded by feathers), which causes poor correspondence between measured and theoretical light curves. The method used thus aims at taking into consideration these errors as well as some other external parameters such as the fact that seabirds do not cross large pieces of land. One other important parameter is the utilization of the recorded temperature from the logger, which is compared to satellite-derived sea surface temperature (SST) maps (Teo et al. 2004; Shaffer et al. 2005). SST was extracted from the raw temperature data, as being stable successive readings of temperatures within a reasonable range of possible SST. The method consists in transforming each estimate of position into a cloud of possible locations, distributed in relation to the method's error. Each of these locations (or particles) is then weighed in relation to a number of parameters such as being on land or not, having a good matching SST or not. From this cloud of particles, the model ran a number of biased random walks. The spread of these model iterations allowed us to visualize, not one track, but a number of possible tracks. This spread is therefore very helpful in interpreting the data, since it can be understood as a likelihood of presence.

\section{FORAGING BEHAVIOUR ANALYSIS}

Diving behaviour was analysed from pressure data using the software MultiTrace-Dive (Jensen Software Systems, Laboe, Germany). Due to limited tag memory and the extended recording period, the sampling frequency was set to eight minutes. This sampling rate 
precluded detailed analysis of diving behaviour in these species for which dives usually last less than 2 minutes (Tremblay et al. 2003; Takahashi et al. 2008). Nevertheless, it allowed identification of foraging phases, defined as periods during which birds performed successive diving bouts. Only dives to depths $>3 \mathrm{~m}$ were analyzed (Elliott et al. 2008). Following Gentry and Kooyman (1986), we defined foraging phases as periods of successive recorded dives interrupted by surface time greater than $37 \mathrm{~min}$ for Brünnich's guillemots and greater than 50min for common guillemots (such inter-foraging phases were spent either resting at the water surface or flying). We also collected information on maximum dive depth.

\section{BIO-ENERGETIC ANALYSIS}

Seabird daily energy requirements were estimated throughout the non-breeding period using Niche Mapper ${ }^{\mathrm{TM}}$. This thermodynamic model, designed to investigate energy balance and energy transfers in a variety of animals, has been previously described in detail (Porter \& Mitchell 2006; Fort et al. 2011) and validated for wintering seabirds, including guillemots (Fort et al. 2009). This model is composed of two different sub-models: a climate model that calculates local microclimate, and an endotherm model which uses local environmental parameters generated by the microclimate sub-model, as well as morphological, physiological and behavioural characteristics of the animal to ultimately estimate bird energy requirements. In this study, Niche Mapper ${ }^{\mathrm{TM}}$ was used to estimate energy requirements for individual adult birds for the Julian day at the centre of each week throughout the non-breeding season. Birds' morphological and physiological properties used as input data are those described for Brünnich's guillemots in Fort et al. (2009); these two guillemot species being very similar morphologically (Gaston \& Jones 1998). 


\section{Climate data}

From light-level geolocation data, we calculated the average weekly location of each bird throughout the non-breeding period and determined climate conditions associated with these locations and therefore encountered by individuals. These climate parameters were maximum and minimum water and air temperatures, wind speed and relative humidity (ICOADS monthly data for $2^{\circ} \times 2^{\circ}$ boxes provided by NOAA/OAR/ESRL PSD, Boulder, Colorado, USA, (http://www.cdc.noaa.gov/)). All climate data associated with bird locations were then entered into the climate sub-model. Common guillemots spent all the non-breeding season at high latitude, exposed during several weeks to a continuous darkness period (this study). During this period at such high latitudes, the precision of the geolocators is affected and the range of possible locations less accurate. Therefore, we considered that all common guillemots spent the entire non-breeding season within an area between $65-75^{\circ} \mathrm{N}$ and $12-40^{\circ} \mathrm{E}$ (see results).

\section{Behavioural properties}

Conduction, convection, evaporation, solar and infrared radiation affect heat loss, heat gain, and energy expenditure. These processes are affected by the physical characteristics of the media surrounding the bird's body during its different activities (flying in air, diving under water, or resting at the water surface). Bird behavioural parameters (flying, diving, and resting as defined above) therefore need to be incorporated into Niche Mapper ${ }^{\mathrm{TM}}$, as well as air and water temperatures, flight altitude, dive depth and flight speed (see Fort et al. 2009, 2011). The proportion of time spent in foraging phases was estimated weekly using recorded diving behaviours (see above). The proportion of time spent flying cannot be estimated for guillemots from temperature recordings of leg-mounted devices because, during winter, birds spend undefined lengths of flight time with their feet either in the air, or in the (warmer) plumage (Linnebjerg et al. unpublished). Based on published data concerning the breeding season (Falk et al., 2000; Falk et al., 2002) and unpublished data for the winter period (Gaston 
\& Elliott unpublished), inter-breeding Brünnich's and common guillemots were assumed to spend $5 \%$ of their time flying when not migrating, and $15 \%$ during the migration periods. These migration periods for Brünnich's guillemots were defined from the obtained GLS positions (see results) as extending from mid-September to end-November for the autumn migration and from mid-February to mid-March for the spring migration (Supplementary material Appendix 1).

\section{STATISTICAL ANALYSIS}

Statistics for behavioural and energetic results were computed in R 2.11.1 (R Development Core Team, 2010). The effects of time through the non-breeding period on all recorded variables were analyzed using linear mixed-effects models (lme) fitted by residual maximum likelihood for repeated measures analyses (REML). In these analyses, 'weeks' were entered as fixed factors, and 'bird' as a random factor. This method accounted for the fact that we were dealing with time series. All data are presented as mean \pm S.E.

\section{Results}

\section{BRÜNNICH'S GUILLEMOTS}

\section{Migration patterns}

In mid-September, Brünnich's guillemots performed a southward migration to overwinter about $2500 \mathrm{~km}$ from their colony, off south-east Greenland and between Iceland and the UK

(Fig. 1, Supplementary material Appendixes 1 and 2). One individual stayed along the Norwegian coast during winter (Supplementary material Appendix 2). 


\section{Foraging behaviour}

The foraging behaviour of Brünnich's guillemots varied markedly during the non-breeding season.

Average weekly maximum dive depth showed significant variability throughout this period $\left(F_{36,144}=11.14 ; P<0.001\right)$, following a quadratic relationship $\left(r^{2}=0.51 ;\right.$ Fig. 2$)$. Indeed, it increased progressively from September to December (from $67 \pm 8 \mathrm{~m}$ to $171 \pm 11 \mathrm{~m}$ ). It then generally decreased from January until the end of the non-breeding season to reach $48 \pm 2 \mathrm{~m}$ at the end of May (Fig. 2).

The number of foraging phases per week also varied significantly across the non-breeding season $\left(F_{36,144}=2.70 ; P<0.001\right.$; Fig 2$)$. After a slight increase until November $(\mathrm{min}=22.6 \pm 3.6$, $\max =28.2 \pm 2.6$ ), it decreased to reach a minimum in early December at $15.6 \pm 1.4$ foraging phases per week. This variable remained relatively constant during the winter period and increased again from the end of February to late May (from 15.4 \pm 1.9 to 26.0 \pm 5.5 ; Supplementary material Appendix 3). Spring values were similar to those observed in the fall. However, the mean duration of these foraging phases followed a reverse, significant trend $\left(F_{36,144}=3.14 ; P<0.001\right.$; Supplementary material Appendix 3$)$. Indeed, the mean foraging phase duration was low and constant during the first few weeks (from mid-September to endOctober: mean $=65.3 \pm 9.5 \mathrm{~min}$; Fig 2). At the end of October, and until early-December, this value increased sharply, to reach a maximum duration of $161.3 \pm 24.9 \mathrm{~min}$. The foraging phase duration was then high but much more variable during winter with two peaks in earlyFebruary and early-April, respectively, before decreasing again towards the end of the nonbreeding season (Supplementary material Appendix 3).

\section{Time-budget}

The proportion of time spent within foraging phases per week (product of the number of phases per week over foraging phase duration) varied significant according to the date period 
$\left(F_{36,144}=3.96 ; P<0.001\right.$; Fig. 3). Indeed, it progressively increased until the end of November from $9.2 \pm 1.7 \%$ to $20.5 \pm 3.5 \%$. From December to the end of the non-breeding period, the time spent in foraging phases was then relatively constant $($ mean $=21.0 \pm 0.7 \%)$.

On average, Brünnich's guillemots spent a total of 1187 hours involved in foraging phases throughout the non-breeding season.

\section{Daily energy expenditure}

Despite missing geolocation data around the equinoxes precluding energetic calculations for these specific periods, the predicted daily energy expenditure of Brünnich's guillemots presented significant variability across the non-breeding season $\left(F_{27,62}=8.01 ; P<0.001\right.$; Fig. 4$)$. After a stable period in September and October $\left(1236 \pm 22 \mathrm{~kJ} \mathrm{~d}^{-1}\right)$, daily energy expenditure decreased to remain between 1113 and $1207 \mathrm{~kJ} \mathrm{~d}^{-1}$ during the winter period (November to mid-February). It then increased to $1350 \mathrm{~kJ} \mathrm{~d}^{-1}$ with the start of the spring migration before slowly decreasing until the end of the study period (from $1386 \mathrm{~kJ} \mathrm{~d}^{-1}$ early March to $1278 \mathrm{~kJ}$ $\mathrm{d}^{-1}$ late April; $-8 \%$ in 11 weeks).

The total energy expenditure predicted for Brünnich's guillemots across the non-breeding season was on average $2.4 \times 10^{5} \mathrm{~kJ}$ per bird (over 28 weeks). It represents on average $1238 \mathrm{~kJ}$ $\mathrm{d}^{-1}$ per bird.

\section{COMMON GUILLEMOTS}

\section{Migration patterns}

Contrary to Brünnich's guillemots, all common guillemots stayed in a restricted area, close to their colony during the winter (Fig. 1). Indeed, though they moved southward after the breeding season to reach the Norwegian and Russian coasts, they spent the entire nonbreeding season in areas located 200-1000 km from their breeding site (Fig. 1, Supplementary material Appendix 1). Interestingly, our analysis suggests that males and females common 
guillemots were spatially segregated during winter (Supplementary materials Appendix 4). Females were mainly wintering along the Norwegian coast of the Barents Sea and in the White Sea (a previously unsuspected destination with no recoveries of ringed adults, Lorentsen \& May 2012). Males were distributed more eastward along the Norwegian coasts of the Barents and Norwegian Seas (Supplementary materials Appendix 4).

\section{Foraging behaviour}

The average weekly maximum dive depth recorded for common guillemots followed a similar quadratic pattern $\left(r^{2}=0.40\right)$ to that of Brünnich's guillemots, with a significant effect of the considered time-period $\left(F_{36,174}=6.31 ; P<0.001 ;\right.$ Fig. 2$)$. Indeed, maximum dive depth sharply increased after the breeding season and until mid-November $(\min =55 \pm 3 \mathrm{~m}, \max =130 \pm 6 \mathrm{~m})$. It then remained constant, yet with a high inter-individual variability, throughout winter. After this period and until the end of the non-breeding season, maximum dive depth slowly and progressively decreased from $142 \pm 3$ to $90 \pm 7$ meters (Fig. 2).

The mean number of foraging phases per week also presented significant variability through time $\left(F_{36,174}=1.83 ; P=0.006\right.$; Supplementary material Appendix 3$)$. However, after a peak between September and November $(\min =26.1 \pm 2.6, \max =35.7 \pm 1.7)$, it remained constant over a long period until early-April (mean=28.7 \pm 0.3 ). It then increased at the end of the nonbreeding season, yet with high inter-individual variability (Supplementary material Appendix $3)$.

The duration of these foraging phases was also affected by time $\left(F_{36,174}=3.54 ; P<0.001\right)$. It strongly increased during eight weeks, to reach a peak of $165.3 \pm 20.5 \mathrm{~min}$ in mid-November (Supplementary material Appendix 3). The average foraging phase duration then remained constant at $\sim 90$ min per phase, until the end of the non-breeding phase. 


\section{Time-budget}

The proportion of time spent in foraging phases per week in common guillemots was significantly affected by the date period $\left(F_{36,174}=4.48 ; P<0.001\right.$; Fig. 3$)$. From October to December, birds presented a strong increase in their foraging effort which was multiplied by four. Subsequently, the proportion of time spent in foraging phases rapidly decreased and remained relatively constant until the end of the non-breeding season (Fig. 3).

On average, common guillemots individually spent a total of 1321 hours involved in foraging phases throughout the non-breeding season.

\section{Daily energy expenditure}

Predicted daily energy expenditures of common guillemots varied through the non-breeding season $\left(F_{32,122}=749.50 ; P<0.001\right)$ according to encountered climatic conditions, with higher energy constraints during winter and the polar night period (Fig. 4). Across the non-breeding period, common guillemots had a total energy expenditure of $3.0 \times 10^{5} \mathrm{~kJ}$ per bird on average (over 33 weeks). It represents an average of $1293 \mathrm{~kJ} \mathrm{~d}^{-1}$ per bird.

\section{SPECIES COMPARISON}

The weekly foraging effort (proportion of time spent in foraging phases per week) was on average similar between the two species throughout the non-breeding season ( $t$-test; $t=1.70$; $\mathrm{df}=72 ; P=0.09$ ). Despite more flight time, average of weekly energy expenditures of Brünnich's guillemots was similar to the one of common guillemots during the autumn migration period (Mann-Whitney test, $\mathrm{U}=14.0, P=0.12, \mathrm{n}=7$ weeks). During the wintering period, average of energy expenditures was $13.3 \%$ lower in Brünnich's than in common guillemots (Mann-Whitney test, $\mathrm{U}=0.0, P<0.001, \mathrm{n}=12$ weeks). 


\section{Discussion}

By comparing the winter ecology of two closely-related seabird species, our study highlights two divergent migratory strategies in Brünnich's and common guillemots sympatrically breeding on Bjørnøya, Svalbard, and defines how the contrasting environmental conditions encountered affect their foraging behaviour and their energetics. We show that despite an important behavioural plasticity adopted by both species to respond to environmental constraints, the decision to move back-and-forth across the North Atlantic or to spend the winter closer to the breeding sites has important consequences for the winter energy balance of one of the largest groups of wintering seabirds in the North Atlantic.

Despite the fact that we took great care in analyzing behavioural data, our method entails potential biases and we wish to stress that our results on time-energy budget are therefore estimates and should be interpreted carefully. More detailed studies using higher sampling rates over shorter periods and/or new technologies such as accelerometers (Shepard et al. 2008) should now be performed to investigate winter diving and flying behaviours as well as energetics at shorter temporal scales. Yet new technology available today, especially the joint use of geolocators, time-depth recorders and mechanistic models allows extremely useful insights into the ecophysiology of seabirds wintering in the North Atlantic. This permits initial tests of migration theory related to sympatric species, which were so far largely restricted to land birds and waders (e.g. Bearhop et al. 2005; Boyle et al. 2011).

\section{MIGRATING BRÜNNICH'S GUILLEMOTS}

The migratory strategy adopted by Brünnich's guillemots breeding on Bjørnøya allowed them to spend the winter in the Atlantic Ocean, between south Greenland and Faroe Islands (Fig. 1) where climatic conditions (including the photoperiod) are more favourable than further north. Under these conditions, birds displayed significant behavioural plasticity, with important 
differences between the winter period and the rest of the non-breeding season (Fig. 2, Supplementary material Appendix 3). Previous studies showed that Brünnich's guillemots usually forage at depths of 20-50m when breeding, with maximum dive depths $>100 \mathrm{~m}$ (Croll et al. 1992; Falk et al. 2002). Our results confirm these observations, with an average maximum dive depth of about $60 \mathrm{~m}$ mid-September (Fig. 2). Soon after, maximum dive depth increased sharply and remained high during the entire winter period before decreasing in the spring (Fig. 2). Brünnich's guillemots probably modified their behaviour in response to a variation in winter prey availability, either by following prey vertical migration (Godø \& Michalsen 2000; Rowe et al. 2000), and/or by feeding on a different prey type (Falk \& Durinck 1993; Rowe et al. 2000). Further studies investigating guillemot diet along with diving behaviour are necessary to test these different hypotheses. However, observed behavioural changes are unlikely due to variations in climatic conditions encountered during the non-breeding season. Indeed, maximum dive depth is the only measured parameter which varies similarly in common and Brünnich's guillemots. Since these two species experienced very different climatic conditions, day length or light intensity, this similar trend is more likely to be linked to changes in prey vertical availability.

Brünnich's guillemot foraging effort remained high from November to May compared to the breeding season (Fig. 3; Falk et al. 2002). This pattern is similar to those observed in other high-latitude seabirds such as Great cormorants (Grémillet et al. 2005) or European shags (Daunt et al. 2006). It therefore confirms that seabirds generally increase their foraging effort as day length decreases because the altered photoperiod affects both prey availability and seabird visual capabilities (Daunt et al. 2006; White et al. 2008; Regular et al. 2011).

Overall, the migration strategy adopted by Brünnich's guillemots allowed them to achieve slightly lower average and overall energy expenditures than common guillemots across the non-breeding season, yet with large differences predicted between both species during the 
winter period (Fig. 4). Moreover, during winter, these expenditures were low compared to those predicted or measured during their breeding season (Barrett et al. 2002; Benvenuti et al. 2002). This strategy therefore allows Brünnich's guillemots to minimize energetic costs during the season presenting the most challenging environmental conditions.

\section{'RESIDENT' COMMON GUILLEMOTS}

Wintering common guillemots are not strictly resident to their Svalbard breeding grounds, yet they remain within $200-1200 \mathrm{~km}$ of their breeding colonies during the entire non-breeding season, and do not cross the Atlantic (Fig. 1). In these areas of the Norwegian, Barents and White Seas, they face climatic conditions substantially more challenging than those encountered by Brünnich's guillemots off south Greenland, notably through several weeks of continuous darkness that might increase thermoregulatory costs. Consequently, common guillemots responded rather differently to variations of environmental conditions during the study period, both in terms of behaviour and energetics. Hence, their winter foraging behaviour appeared far more stable than that of Brünnich's guillemots (Fig. 2, Supplementary material Appendix 3), except for an activity peak in October/November, which corresponds to the beginning of the polar night. We speculate that birds may then increase their foraging effort and prey intake to achieve their maximum energy reserves (by feeding e.g. on cod: see Huse et al. 2004) before the more challenging polar night period which could affect their foraging efficiency. Indeed, while the maximum dive depths observed during the non-polar night periods were similar between both species, the darker conditions encountered by common guillemots clearly prevented them from foraging as deep as Brünnich's guillemots in a more southerly environment. Furthermore, while the overall non-breeding energy expenditures of the two species were relatively similar, daily estimations showed some interesting variations. Indeed, during the Brünnich's guillemot migration periods, both species 
have very similar energetics, despite the fact that the common guillemots flying activity was greatly reduced. Then, during the harsh winter phase, when both species have equal flight constraints, the residency strategy adopted by studied common guillemots did not allow them to decrease their energy demand, making this period even more challenging. These findings are essential as they confirm the importance of climatic conditions for the energy balance of North Atlantic wintering seabirds (Fort et al. 2009), in particular of common guillemots wintering in the Barents, the Norwegian and the White seas (Fig. 4). Nevertheless, it should be noted that daily energy expenditures of common guillemot during the non-breeding period were lower than those predicted for breeding birds (Barrett et al. 2002).

In conclusion, our comparative study highlights how closely-related, sympatric seabird species can adopt divergent migratory strategies, and demonstrates their varied consequences for seabird behaviour and energetics. Focused on wintering common and Brünnich's guillemots from Bjørnøya, it suggests that, in terms of long-term energetics, both southward migration and high-arctic winter residency are relatively equivalent and suitable. Nevertheless, on a day-to-day scale, the migratory strategy adopted by Brünnich's guillemots allows them to have reduced energy expenditures during the more challenging core-winter period, and might therefore present an important advantage. Every winter, hundreds of seabirds unable to cope with extreme climatic conditions and high energy constraints die of starvation during winter wrecks (Gaston 2004, Fort et al. 2009). Because of their inability to decrease their high energy requirements during winter, northern common guillemots appear more liable to face an energetic bottleneck and to be confronted by these mass-mortality events. It would nevertheless now be important to investigate the quality of food available for both species at their wintering sites. Indeed, prey with higher calorific content could, if more available to common than to Brünnich's guillemots, reduce this difference by 
counterbalancing the higher energy expenditure of common guillemots, and allowing both species to balance their energy budgets.

\section{Acknowledgements}

We thank Grégoire Kuntz, Erlend Lorentsen, Magnus Irgens, Sigrid Engen and all assistants for their hard work in the field. We are grateful to Yvon Le Maho and Geir W. Gabrielsen for their support in this project. We also thank J. Linnebjerg, M. Frederiksen, S. Bearhop and S. Votier for comments on an earlier version of the manuscript. Funding for this study was provided by the TOTAL Foundation and TOTAL Norway within the framework of the BarentsBirds Project led by Harald Steen and David Grémillet. Jérôme Fort was supported by a grant from the Fyssen Foundation.

\section{References}

Bakken, V. and Mehlum, F. 2005. Wintering areas and recovery rates of Brünnich's guillemots Uria lomvia ringed in the Svalbard archipelago. Arctic 58: 268-275.

Bakken, V. and Pokrovskaya, I. V. 2000. Brünnich's guillemot Uria lomvia. In The status of marine birds breeding in the Barents Sea region (ed. T. Anker-Nilssen, V. Bakken, H. Strøm, A. N. Golovkin, V. V. Bianki \& I. Tararinkova), pp. 119-124. Norwegian Polar Institute: Tromsø.

Barrett, R. T., Anker-Nilssen, T., Gabrielsen, G. W. and Chapdelaine, G. 2002. Food consumption by seabirds in Norwegian waters. ICES J. Mar. Sci. 59: 43-57.

Barrett, R. T. and Golovkin, A. N. 2000. Common guillemot Uria aalge. In The status of marine birds breeding in the Barents Sea region (ed. T. Anker-Nilssen, V. Bakken, H. Strøm, A. N. Golovkin, V. V. Bianki \& I. Tararinkova), pp. 114-118. Norwegian Polar Institute: Troms $\emptyset$. 
Bearhop, S., Fiedler, W., Furness, R. W., Votier, S. C., Waldron, S., Newton, J., Bowen, G. J., Berthold, P. and Farnsworth, K. 2005. Assortative mating as a mechanism for rapid evolution of a migratory divide. Science 310: 502-504.

Benvenuti, S., Dall'Antonia, L. and Falk, K. 2002. Diving behaviour differs between incubating and brooding Brünnich’s guillemots, Uria lomvia. Polar Biol. 25: 474-478.

Berthold, P., Gwinner, E. and Sonnenschein, E. 2003. Avian Migration. Springer-Verlag, Berlin.

Boyle, W. A., Conway, C. J. and Bronstein, J. L. 2011. Why do some, but not all, tropical birds migrate? A comparative study of diet breadth and fruit preference. Evol. Ecol. 25: 219-236.

Brooke, M. de L. 2004. The food consumption of the world's seabirds. Proc. R. Soc. B. 271: S246-S248.

Croll, D. A., Gaston, A. J., Burger, A. E. and Konnoff, D. 1992. Foraging behavior and physiological adaptation for diving in thick-billed murres. Ecology 73: 344-356.

Daunt, F., Afanasyev, V., Silk, J. R. D. and Wanless, S. 2006. Extrinsic and intrinsic determinants of winter foraging and breeding phenology in a temperate seabird. Behav. Ecol. Sociobiol. 59: 381-388.

Egevang, C., Stenhouse, I. J., Phillips, R. A., Petersen, A., Fox, J. W. and Silk, J. R. D. 2010. Tracking of Arctic terns Sterna paradisaea reveals longest animal migration. Proc. Natl. Acad. Sci. U.S.A. 107: 2078-2081.

Elliott, K. H., Davorren, G. K. and Gaston, A. J. 2008. Time allocation by a deep-diving bird reflects prey type and energy gain. Anim. Behav. 75: 1301-1310

Falk, K. and Durinck, J. 1993. The winter diet of thick-billed murres, Uria lomvia, in western Greenland, 1988-1989. Can. J. Zool. 71: 264-272. 
Falk, K., Benvenuti, S., Dall'Antonia, L., Kampp, K. and Ribolini, A. 2000. Time allocation and foraging behaviour of chick-rearing Brünnich's Guillemots Uria lomvia in higharctic Greenland. Ibis 142: 82-92.

Falk, K., Benvenuti, S., Dall'Antonia, L., Gilchrist, G. and Kampp, K. 2002. Foraging behaviour of thick-billed murres breeding in different sectors of the North Water polynya: an inter-colony comparison. Mar. Ecol. Prog. Ser. 231: 293-302.

Fort, J., Porter, W. P. and Grémillet, D. 2009. Thermodynamic modelling predicts energetic bottleneck for seabirds wintering in the northwest Atlantic. J. Exp. Biol. 212: 24832490.

Fort, J., Porter, W. P. and Grémillet, D. 2011. Energetic modelling: A comparison of the different approaches used in seabirds. Comp. Biochem. Physiol. A 158: 358-365.

Fort, J., Beaugrand, G., Grémillet, D. and Phillips, R. A. P. 2012. Biologging, satellite oceanography and the Continuous Plankton Recorder reveal the environmental determinants of a seabird wintering hotspot in the North Atlantic. PLoS ONE. 7(7): e41194.

Gaston, A. J. 2004. Seabirds - a natural history. Yale University Press, London.

Gaston, A. J. and Jones, I. L. 1998. Bird families of the world: the auks. Oxford University press, Oxford.

Gentry, R. L. and Kooyman, G. L. 1986. Methods of dive analysis. Fur seals - Maternal strategies on land and at sea (eds R.L Gentry \& G.L. Kooyman), pp 28-40, Princeton University Press, New Jersey.

Godø, O. R. and Michalsen, K. 2000. Migratory behaviour of north-east Arctic cod, studied by use of data storage tags. Fish. Res. 48: 127-140.

Grémillet, D., Kuntz, G., Woakes, A. J., Gilbert, C., Robin, J. P., Le Maho, Y. and Butler, P. 2005. Year-round recording of behavioural and physiological parameters reveal the 
survival strategy of a poorly insulated diving endotherm during the Arctic winter. J. Exp. Biol. 208: 4231-4241.

Huse, G., Johansen, G. O., Bogstad, B., and Gjøsæter, H. 2004. Studying spatial and trophic interactions between capelin and cod using individual-based modelling. ICES J. Mar. Sci. 61: 1201-1213.

Klaassen, M. 1996. Metabolic constraints on long-distance migration in birds. J. Exp. Biol. 199: 57-64.

Klaassen, M. 2003. Relationships between migration and breeding strategies in arctic breeding birds. Avian migration. (eds P. Berthold, E. Gwinner \& E. Sonnenschein), pp. 237-249, Springer-Verlag, Berlin.

Lebreton, J. D., Burnham, K. P., Clobert, J. and Anderson, D. R. 1992. Modelling survival and testing biological hypotheses using marked animals: a unified approach with case studies. Ecol. Monogr. 62: 67-118.

Lorentsen S-H. and May R. 2012. Inter-breeding movements of common guillemots (Uria aalge) suggest the Barents Sea is an important autumn staging and wintering area. Polar Biol. 35: 1713-1719.

Maldonado, K. E., Cavieres, G., Veloso, C., Canals, M. and Sabat, P. 2009. Physiological responses in rufous-collared sparrows to thermal acclimation and seasonal acclimatization. J. Comp. Physiol. B 179: 335-343.

McNamara, J. M., Barta, Z., Wikelski, M. and Houston, A. I. 2008. A theoretical investigation of the effect of latitude on avian life histories. Am. Nat. 172: 331-345.

McWilliams, S. R., Guglielmo, C., Pierce, B. and Klaassen, M. 2004. Flying, fasting, and feeding in birds during migration: a nutritional and physiological ecology perspective. J. Avian Biol. 35: 377-393. 
Møller, A. P. 1994. Phenotype-dependent arrival time and its consequences in a migratory bird. Behav. Ecol. Sociobiol. 35: 115-122.

Newton, I. 2008. The migration ecology of birds. Academic Press, London

Porter, W. P. and Mitchell, J. W. 2006. Method and system for calculating the spatialtemporal effects of climate and other environmental conditions on animals. http://www.patentstorm.us/patents/7155377-fulltext.html (ed. U.P Office). Wisconsin Alumni Research Foundation, USA.

Regular, P.M., Hedd, A. and Montevecchi, W.A. 2011. Fishing in the Dark: A Pursuit-Diving Seabird Modifies Foraging Behaviour in Response to Nocturnal Light Levels. PLoS ONE 6:e26763.

Rolshausen, G., Hobson, K. A. and Schaefer, H. M. 2010. Spring arrival along a migratory divide of sympatric blackcaps (Sylvia atricapilla). Oecologia 162: 175-183.

Rowe, S., Jones, I. L., Chardine, J. W., Elliot, R. D. and Veitch, B. G. 2000. Recent changes in the winter diet of murres (Uria spp.) in coastal Newfoundland waters. Can. J. Zool. 78: $495-500$.

Shaffer, S. A., Tremblay, Y., Awkerman, J. A., Henry, R. W., Teo, S. L. H., Anderson, D. J., Croll, D. A., Block, B. A. and Costa, D. P. 2005. Comparison of light- and SST-based geolocation with satellite telemetry in free-ranging albatrosses. Mar. Biol. 147: 833843.

Shepard, E. L. C., Wilson, R. P., Quintana, F., Gómez Laich, A., Liesbech, N.,Albareda, D. A., Halsey, L. G., Gleiss, A., Morgan, D. T., Myers, A. E., Newman, C. and Macdonald, D. W. 2008. Identification of animal movement patterns using tri-axial accelerometry. Endang. Species Res. 10: 47-60. 
Takahashi, A., Matsumoto, K., Hunt, G. L., Shultz, M. T., Kitaysky, A. S., Sato, K., Iida, K. and Watanuki, Y. 2008. Thick-billed murres use different diving behaviors in mixed and stratified waters. Deep Sea Res. II 55: 1837-1845.

Teo, S. L. H., Boustany, A., Blackwell, S. B., Walli, A., Weng, K. C. and Block, B. A. 2004. Validation of geolocation estimates based on light level and sea surface temperature from electronic tags. Mar. Ecol. Prog. Ser. 283: 81-98.

Tremblay, Y., Cherel, Y., Oremus, M., Tveraa, T. and Chastel, O. 2003. Unconventional ventral attachment of time-depth recorders as a new method for investigating time budget and diving behaviour in seabirds. J. Exp. Biol. 206: 1929-1940.

Tremblay, Y., Robinson, P. W. and Costa, D. P. 2009. A parsimonious approach to modeling animal movement data. Plos One 4: e4711.

White, C. R., Butler, P. J., Grémillet, D. and Martin, G. R. 2008. Behavioural strategies of cormorants (Phalacrocoracidae) foraging under challenging light conditions. Ibis 150 (S1): 231-239.

Wilson, R. P., Duchamp, J. J., Rees, W. G., Culik, B. M. and Niekamp, K. 1992. Estimation of location: global coverage using light intensity. In Wildlife telemetry: remote monitoring and tracking of animals (ed. I. M. Priede \& S. M. Swift), pp. 131-134. Chichester: Ellis Howard. 


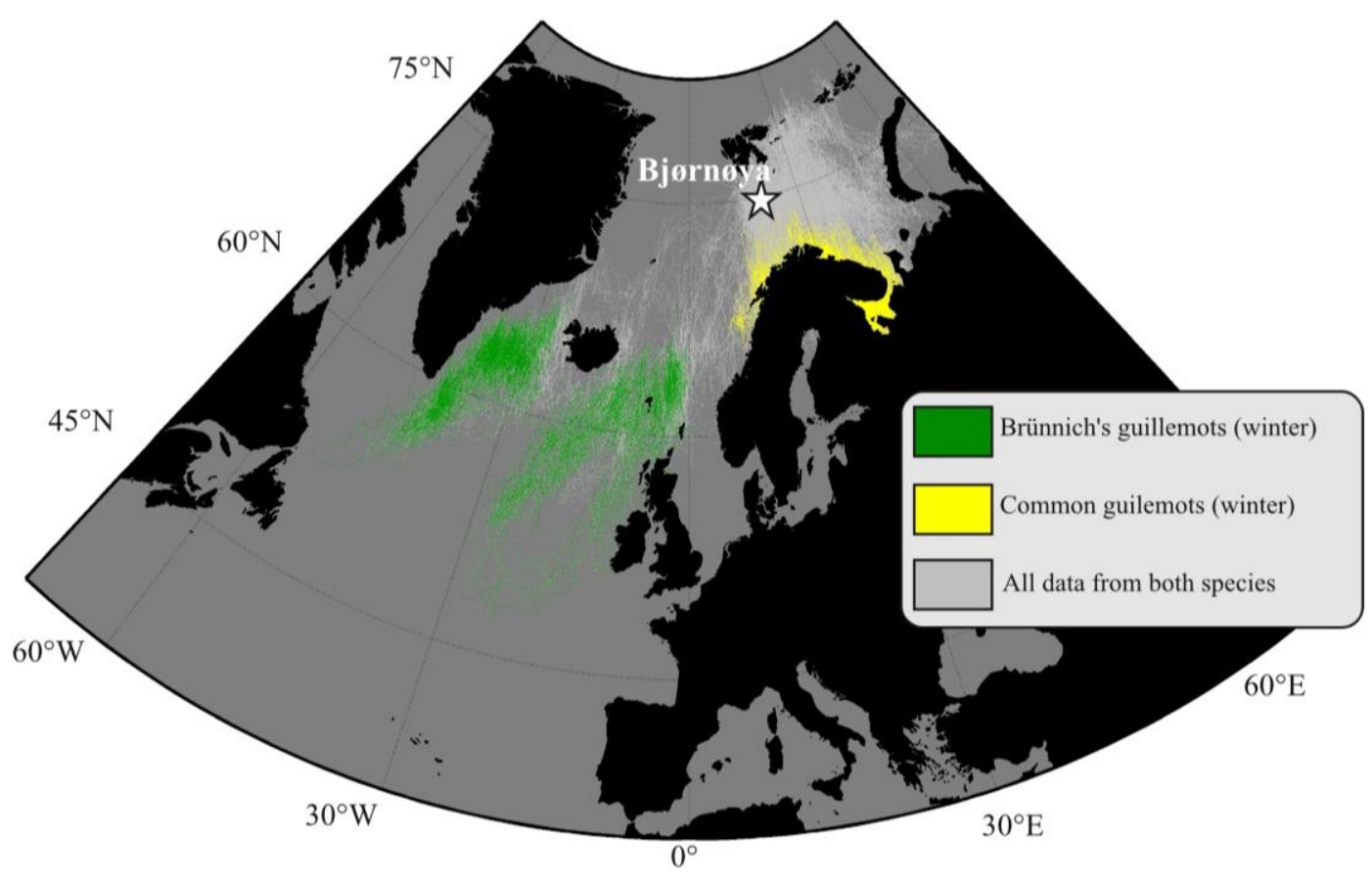

Figure 1. Wintering (1 December - 31 January) grounds of Brünnich's guillemots $(n=5)$ and common guillemots $(n=7)$ breeding on Bjørnøya, Svalbard and tracked by GLS during the 2007-2008 non-breeding season. The star represents the breeding colony. Map projection: Albers equal area conic. 

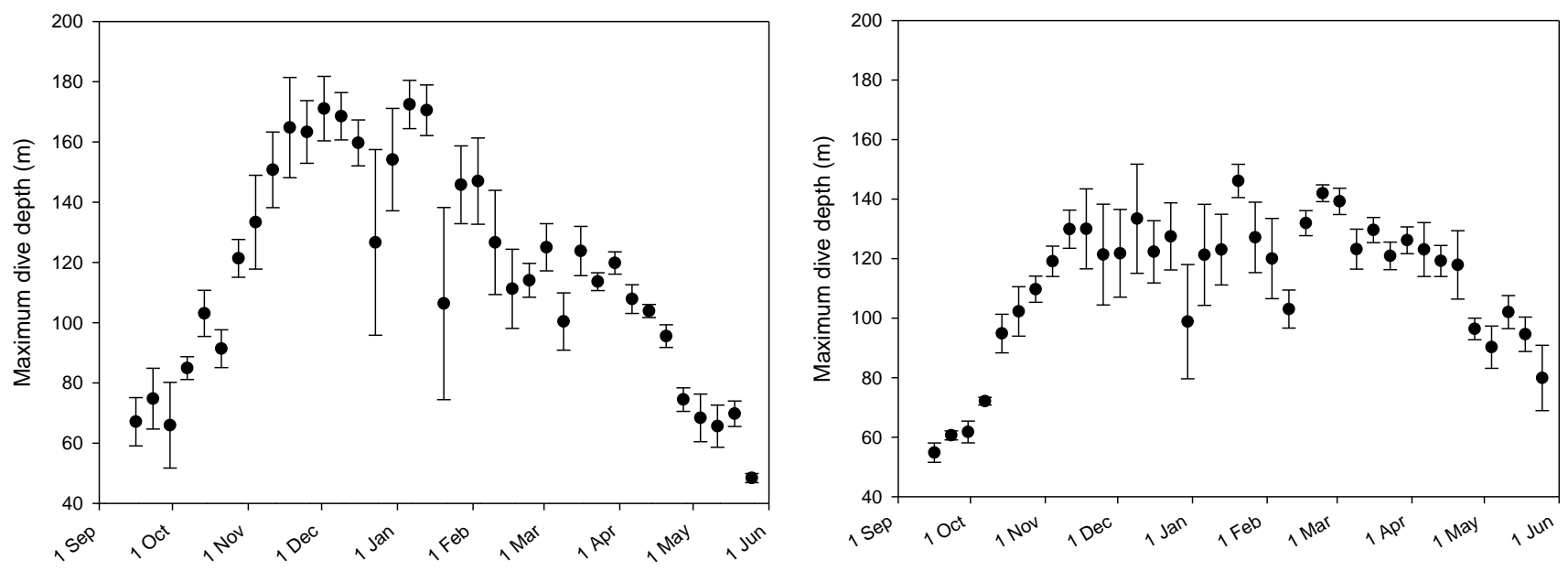

Figure 2. Weekly maximum foraging dive depth of Brünnich's $(n=5)$ and common guillemots $(n=6)$ throughout the non-breeding season. Values are $\pm S E(n=5-12)$. The continuous line indicates the period during which common guillemots are exposed to the polar night at $72^{\circ} \mathrm{N}$. 

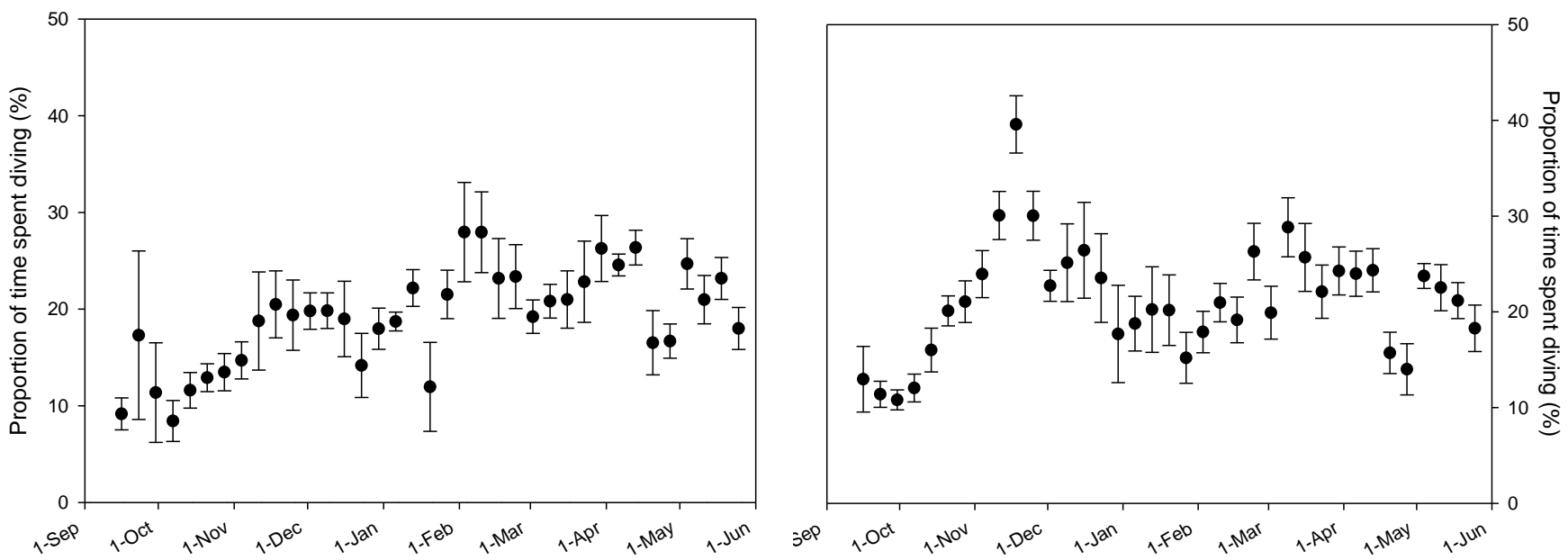

Figure 3. Weekly foraging effort (time spent diving) of Brünnich's (n=5) and common guillemots $(\mathrm{n}=6)$ throughout the non-breeding season. Values are $\pm \mathrm{SE}$ 


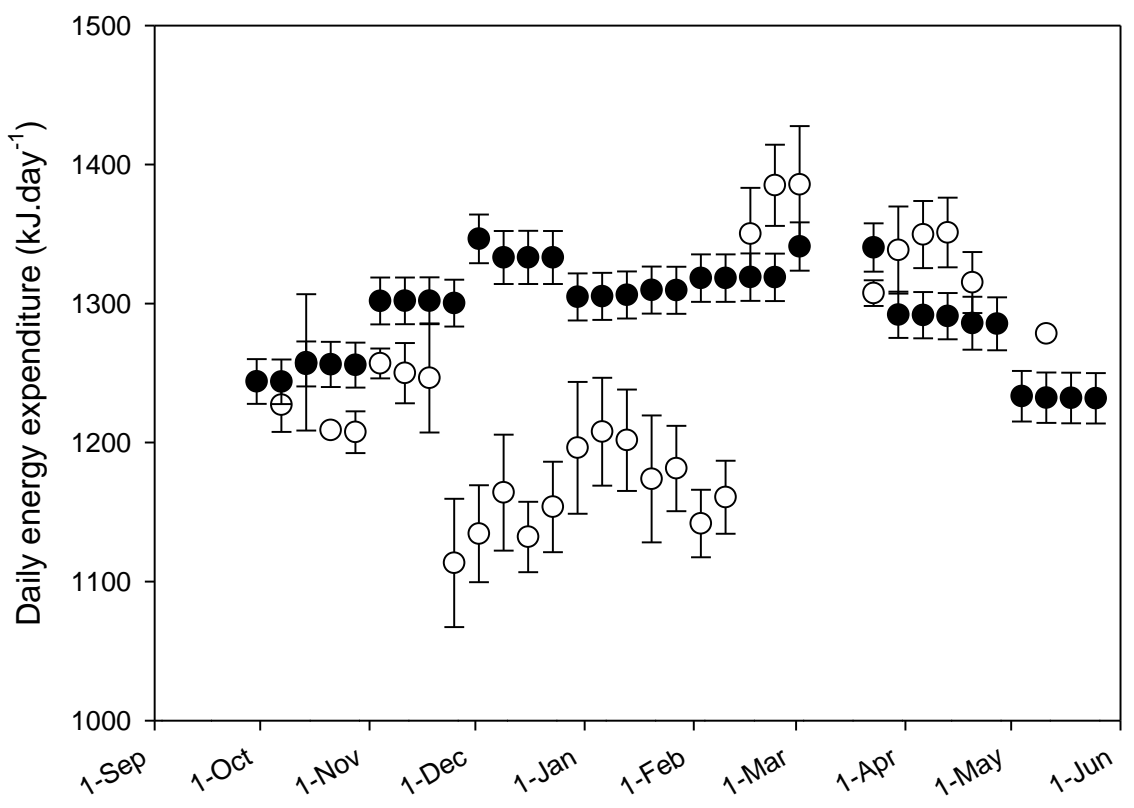

Figure 4. Predicted daily energy expenditure of Brünnich's (open circles; $n=4$ ) and common guillemots (filled circles; $n=5$ ) throughout the non-breeding season. Values are \pm SE. No value was calculated for the equinox periods. Each data point represents the estimated expenditure for the Julian day at the centre of each week. 


\section{Supplementary material}

\section{Appendix 1}

Weekly distance to the colony of origin for tracked Brünnich's guillemots (red, n=5) and common guillemots (blue, $n=7$ ). On each box, the central mark is the median, the edges of the box are the 25th and 75th percentiles, the whiskers extend to the most extreme data points not considered outliers, and outliers are plotted individually.

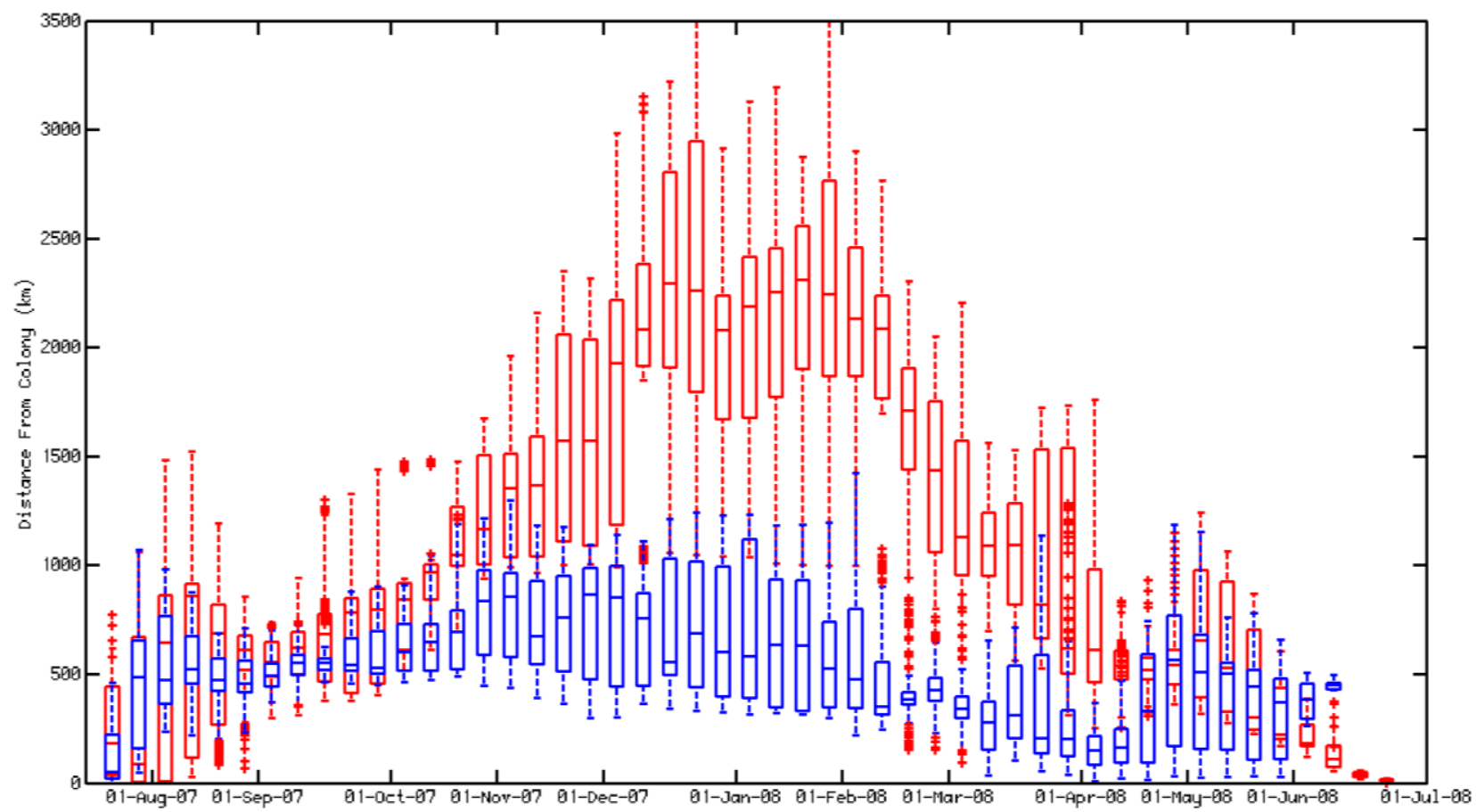




\section{Appendix 2}

Individual winter (December and January) distribution of Brünnich's (A) and common guillemots (B). Each individual is represented by a different colour. The white point shows the breeding colony. Map projection: Albers equal area conic.






\section{Appendix 3}

Weekly foraging behaviour of Brünnich's and common guillemots ( $\mathrm{n}=5$ and $\mathrm{n}=7$, respectively) throughout the non-breeding season. Values are \pm SE. The continuous line indicates the period during which common guillemots are exposed to the polar night at $72^{\circ} \mathrm{N}$.

Brünnich's guillemots

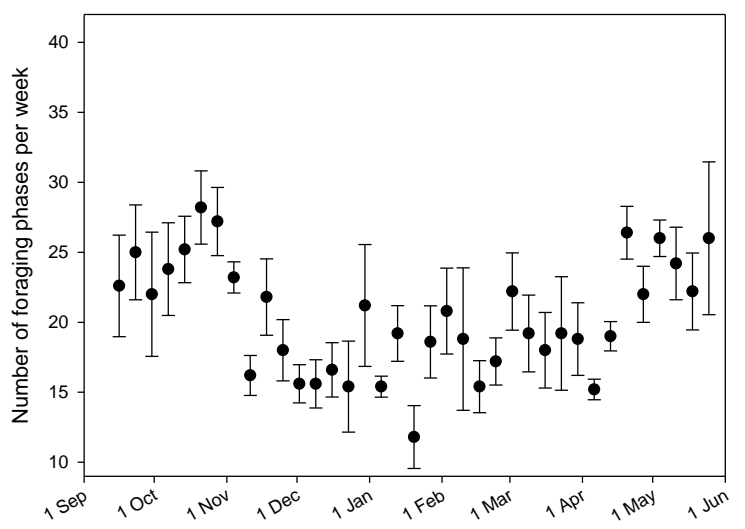

Brünnich's guillemots

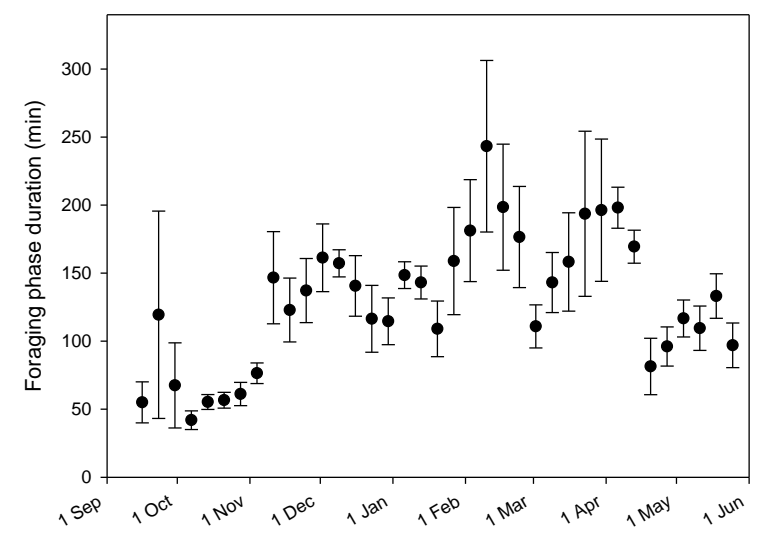

Common guillemots

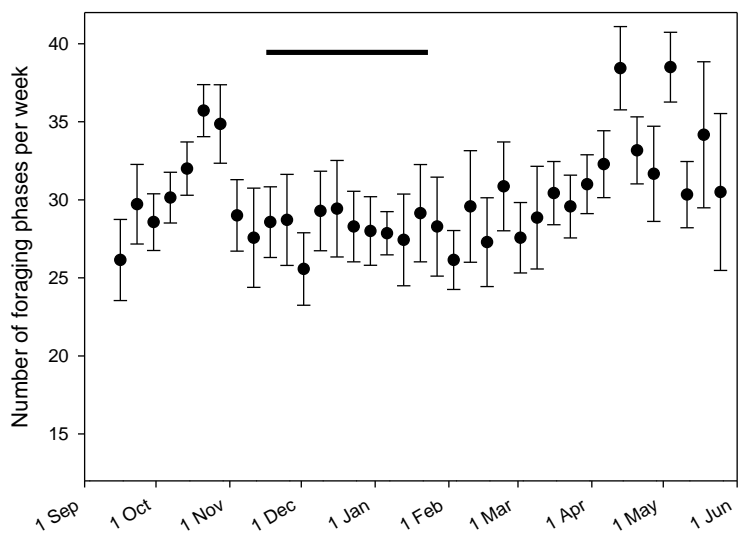

Common guillemots

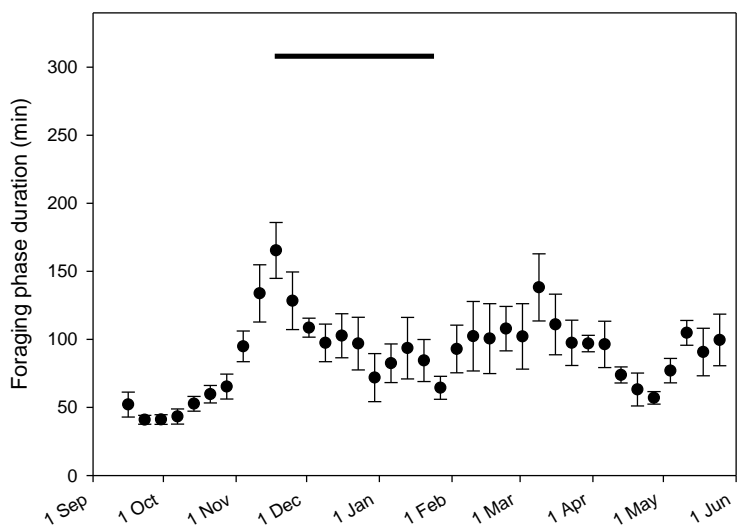




\section{Appendix 4}

Winter (December and January) distribution of Brünnich's (A) and common guillemots (B) by sex. Males and females are represented in blue and pink, respectively. The white point shows the breeding colony. Map projection: Albers equal area conic.
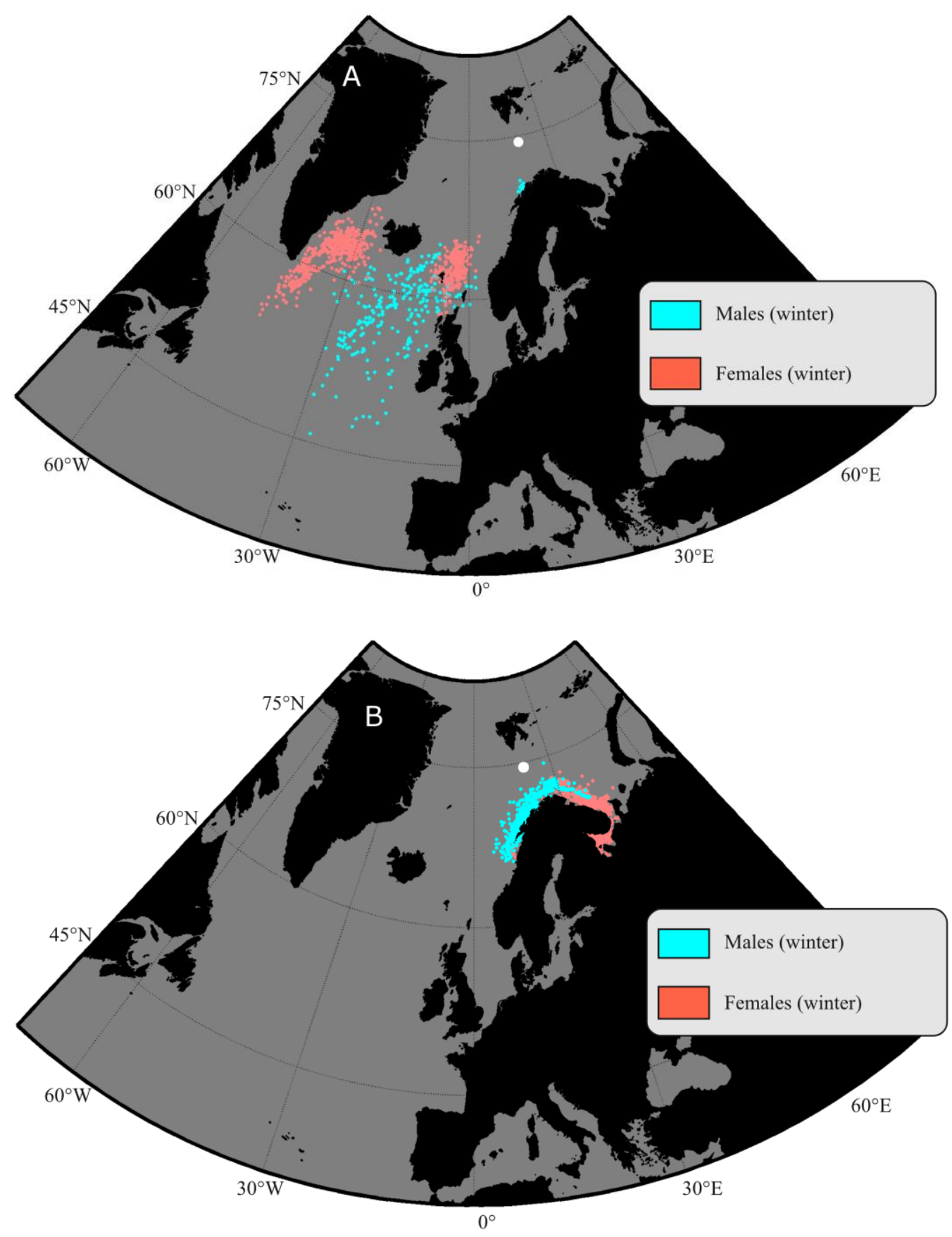